\title{
The estimated prevalence of chronic obstructive pulmonary disease in a general practice population
}

\author{
*Timothy L Frank, Michelle L Hazell, Mary F Linehan, Julie A Morris, Peter I Frank
}

General Practice Research Unit, North West Lung Research Centre, Wythenshawe Hospital, Manchester, M23 9LT, UK

Received 4th October 2006; accepted 2nd February 2007

\begin{abstract}
Objective: To estimate the prevalence of chronic obstructive pulmonary disease (COPD) in a general practice population in the UK.

Method: Four postal respiratory questionnaire surveys were carried out between 1993 and 2001. Subjects from the 2001 study were invited for spirometry if they were aged 30 years or more, had indicated that they were 'ever smokers' in any of the surveys, and/or had been considered to have likely obstructive airways disease on the basis of their replies to the 2001 questionnaire.

Results: 2646 subjects were invited for spirometry of whom 871 (32.9\%) attended. Results were available for 825 participants. 163 of these subjects were categorised as having COPD. The estimated prevalence in the whole population was $4.1 \%$ with the highest prevalence (14.7\%) in those aged 60-69 years. In those aged over 40 years it was $9.6 \%$

Conclusion: This study suggests that the prevalence of COPD is much higher than the previous estimates of between 1 and $2 \%$.

(C) 2007 General Practice Airways Group. All rights reserved

TL Frank, et al. Prim Care Resp J 2007; 16(3): 169-173.

doi:10.3132/pcrj.2007.00028
\end{abstract}

Keywords COPD, prevalence, general practice

\section{Introduction}

Globally, chronic obstructive pulmonary disease (COPD) will be the fifth leading cause of disability in the first half of the 21 st century. ${ }^{1}$ COPD is also the fourth leading cause of death in the USA and Europe. ${ }^{2}$ The prevalence and morbidity data greatly underestimate the total burden of COPD because the disease is usually not diagnosed until it is clinically apparent and moderately advanced. ${ }^{3}$ Objective information from the UK concerning COPD prevalence is scarce. In 1995 the Office of Population Censuses and Surveys estimated prevalence for COPD in the population at $1 \%,{ }^{4}$ and a study using the General Practice Research Database (GPRD), which collects data from 525 general practices with an overall population of 3.4 million, quoted the prevalence of diagnosed COPD in 1997 as being $1.4 \%$ for women and $1.7 \%$ for men. ${ }^{5}$ It was reported that these were the lowest estimates of the population burden of COPD in the UK, because less severe COPD is often not diagnosed and these patients are not identified in the GPRD system. The only published UK study using spirometry in a general practice population examined only those aged 60 to 75 years of age. ${ }^{6}$

The aim of the present study was to determine the prevalence of COPD - diagnosed by spirometry - in two general practice populations in South Manchester by inviting at risk patients to attend for evaluation.

\section{Method}

The study forms part of the Wythenshawe Community Asthma Project (WYCAP), a long-term survey examining the natural history of respiratory symptoms in general practice. Postal respiratory questionnaires were sent to all registered patients on four separate occasions, in 1993, 1995, 1999, and $2001 .^{7}$ The practices are situated on a housing estate in Manchester with high levels of socioeconomic deprivation. ${ }^{8}$ The questionnaire ${ }^{9}$ used for patients aged sixteen years and over was based on the European Community Respiratory Health Questionnaire. ${ }^{10}$ A different questionnaire was used for children, the results of which will not be considered further here. Reminders were sent to non-responders after four and eight weeks for each survey. A simple scoring system

*Corresponding author: Tel: +44 (0)161 2915044 Fax: +44 (0)161 2915047 Email: gpresearchunit@yahoo.co.uk 
was developed and validated to identify subjects with likely obstructive airways disease (OAD)." Those with four or more symptoms or risk factors from six key questions - the presence of wheezing, being woken by cough, being woken by chest tightness, being woken by shortness of breath (all in the previous 12 months), a history of hay fever or eczema, and a family history of asthma - were categorised as having likely OAD. The system did not differentiate COPD and asthma.

For the present study, eligible patients ${ }^{9}$ were approached for spirometry either opportunistically (when they consulted at their surgery), by telephone (by the practice nurses), or by letter (if no telephone number was available), if they:

- had replied to the 2001 survey AND

- were aged 30 years or more at the time of the 2001 survey AND

- had indicated in any of the four surveys that they were current or ex-smokers AND/OR reported four or more symptoms or risk factors in the 2001 survey (i.e. were likely to have OAD)

Informed oral consent to participate in the study was obtained at the spirometry appointment. Participants were seen over an 18-month period at the practice surgeries; the practice nurses, all of whom had received special training in spirometry, carried out interviews and measurements. As the last postal questionnaire had been completed more than one year before the spirometry testing, participants were asked to complete a new respiratory questionnaire. ${ }^{9}$ The analyses for the present study used the data from this last questionnaire. Additional smoking history was recorded by direct questioning. Current and ex-smokers were asked about their daily consumption and the number of years they had smoked. Spirometry methods and reversibility testing have been described in the previous paper ${ }^{9}$; spirometry was carried out using a MicroLoop spirometer (Micro Medical Ltd, Rochester $U K)$. Forced expiratory volume in one second $\left(\mathrm{FEV}_{1}\right)$, forced vital capacity (FVC), and the $\mathrm{FEV}_{1} / \mathrm{FVC}$ ratio were measured.

The definition of COPD used in this study was based on spirometry testing in accordance with the 2003 GOLD criteria. ${ }^{2}$ Subjects with GOLD stage 2-4 disease were classified as having COPD ( $\mathrm{FEV}_{1}<80 \%$ predicted and $\mathrm{FEV}_{1} / \mathrm{FVC}$ ratio $<70 \%$ after bronchodilatation).

South Manchester Local Research Ethics Committee approved this study.

\section{Analysis}

Subjects aged between 30 and 79 years who attended for spirometry were grouped into 10 -year age bands; those aged 80 and over were combined into a single category. Individuals under 30 years were assumed not to have COPD and were not invited for spirometry.

The measured prevalence of study-diagnosed COPD was the prevalence of COPD diagnosed at the study spirometry visit using the total population as the denominator.

The estimated prevalence of COPD was calculated for the separate age groups based on data from attenders corrected for spirometry non-attendance and also for non-response to the postal questionnaire. It was assumed firstly that those not attending for spirometry but who had been invited (and were therefore at risk of COPD) had the same risk of disease as those attending; and secondly, that those not responding to the postal questionnaire had the same prevalence of disease within the individual age groups as responders. Predicted numbers of patients with and without COPD were thus calculated for each age group and the prevalence calculated for the population using the total population as the denominator.

\section{Estimation of prevalence of COPD}

For responders to the 2001 survey, this was done in three stages:

1) The actual number (A) of subjects who had spirometry testing compatible with a diagnosis of COPD was determined for each age group, and the prevalence was determined using the whole population as the denominator.

2) Assuming that those invited, but who did not attend for spirometry (therefore being 'at risk'), had the same prevalence as those who attended, the number (B) estimated to have COPD in this group was calculated for each age group, using the prevalence data from stage 1.

3) It was assumed that those not invited for spirometry (not at risk of COPD) did not have COPD (C). This will always be equal to zero but is shown here to clarify the methods. The estimated total number of responders with COPD within each age group was thus calculated by adding $A+B+C$.

4) In order to estimate the number of subjects with COPD among non-responders (D) to the 2001 questionnaire, it was assumed that the prevalence in each age group was the same as that among the responders.

The estimated number of patients in the whole population with COPD in each age group is therefore $A+B+C+D$, with the estimated prevalence being calculated using the whole population as the denominator.

Children have been included in the denominator for this calculation since by convention the population prevalence of COPD includes individuals of all ages.

95\% confidence intervals for the estimated number of COPD patients were derived using a Monte Carlo simulation method, ${ }^{13}$ with 1000 simulations, which incorporates the two main sources of sampling variability, namely: the proportion of registered patients who would be invited for spirometry; and the proportion of invited patients who would be diagnosed with COPD, with an appropriate proportionate adjustment for the response rate. 
Table 1. Characteristics of attenders and non-attenders.

\begin{tabular}{llccc} 
& Attenders & Non-attenders & Difference & $95 \% \mathrm{Cl}$ of difference \\
\hline Mean age & $55.6(\mathrm{n}=825)$ & $50.7(\mathrm{n}=1821)$ & 4.9 & 3.74 to 6.08 \\
Sex (\% female) & $54.7(\mathrm{n}=825)$ & $52.9(\mathrm{n}=1821)$ & 1.8 & -2.31 to 5.88 \\
\% smokers 2001 & $65.3(\mathrm{n}=785)$ & $74.9(\mathrm{n}=1735)$ & 9.6 & 5.7 to 13.6 \\
\% with likely OAD & $37.3(\mathrm{n}=775)$ & $31.4(\mathrm{n}=1708)$ & 5.9 & 1.8 to 0.0 \\
\hline
\end{tabular}

\section{Results}

Of the 10,471 adult subjects who were registered with the two practices in 2001, 6828 (65.2\%) responded to the postal questionnaire. Entry criteria for the present study were fulfilled by 2646 respondents (the "at risk group"), all of whom were invited for spirometry. In all, 871 (32.9\%) undertook spirometry, of whom $825(94.7 \%$ - "the attenders") had results which were adequate for analysis and were therefore included in the study. Attenders were significantly older, and there was a higher proportion of subjects with likely OAD than with the non-attenders, who, in turn were more likely to be smokers (Table 1).

The numbers of those in each age group found to have COPD, and the estimated number and resulting prevalence, are shown in Table 2. Spirometry results indicated that 163 patients had COPD. If there were no further cases, then the prevalence in the whole registered adult and child population $(13,654$ individuals) would be $1.2 \%$. If it is assumed that all subjects invited for spirometry, whether or not they attended for the test, had the same prevalence for each age group, and

Table 2. Actual, estimated number of subjects and percentage prevalence amongst all registered patients in 2001 with COPD by age group ( $95 \%$ confidence interval).

\begin{tabular}{|c|c|c|c|c|c|c|c|c|}
\hline Age group & $0-29$ & $30-39$ & $40-49$ & $50-59$ & $60-69$ & $70-79$ & $80+$ & Total \\
\hline Registered patients 2001 & 5790 & 2203 & 1775 & 1491 & 922 & 919 & 554 & 13654 \\
\hline Responders to 2001 survey & 3310 & 1225 & 1124 & 1120 & 796 & 827 & 437 & 8839 \\
\hline Invited for spirometry & 0 & 621 & 620 & 630 & 362 & 304 & 109 & 2646 \\
\hline Adequate spirometry & 0 & 103 & 172 & 241 & 167 & 119 & 23 & 825 \\
\hline $\begin{array}{l}\text { Number with spirometrically } \\
\text { diagnosed COPD (A) }\end{array}$ & 0 & 1 & 20 & 38 & 54 & 44 & 6 & 163 \\
\hline $\begin{array}{l}\text { Estimated number with COPD } \\
\text { in those invited but not attending } \\
\text { for spirometry (B) }\end{array}$ & 0 & 5 & 52 & 61 & 63 & 68 & 22 & 271 \\
\hline $\begin{array}{l}\text { Estimated number with COPD in } \\
2001 \text { questionnaire responders not } \\
\text { invited for spirometry (C) }\end{array}$ & 0 & 0 & 0 & 0 & 0 & 0 & 0 & 0 \\
\hline $\begin{array}{l}\text { Estimated number with COPD in non } \\
\text { responders to } 2001 \text { questionnaire (D) }\end{array}$ & 0 & 5 & 42 & 33 & 19 & 12 & 7 & 118 \\
\hline $\begin{array}{l}\text { Total estimated number } \\
\text { ( } 95 \% \text { confidence interval) }\end{array}$ & 0 & $\begin{array}{c}10.8 \\
(0- \\
33.0)\end{array}$ & $\begin{array}{l}113.8 \\
(67.9- \\
164.3)\end{array}$ & $\begin{array}{l}132.2 \\
(95.2- \\
171.1)\end{array}$ & $\begin{array}{r}135.6 \\
(107.3- \\
165.5)\end{array}$ & $\begin{array}{l}124.9 \\
(97.0- \\
153.6)\end{array}$ & $\begin{array}{c}36 \\
(12.0- \\
64.6)\end{array}$ & $\begin{array}{r}553.5 \\
(479.2- \\
614.2)\end{array}$ \\
\hline $\begin{array}{l}\% \text { Prevalence of COPD } \\
\text { (95\% confidence interval) }\end{array}$ & 0 & $\begin{array}{l}0.5 \\
(0- \\
1.5)\end{array}$ & $\begin{array}{c}6.4 \\
(3.8- \\
9.3)\end{array}$ & $\begin{array}{c}8.9 \\
(6.4- \\
11.5)\end{array}$ & $\begin{array}{r}14.7 \\
(11.6- \\
18.0)\end{array}$ & $\begin{array}{r}13.6 \\
(10.6- \\
16.7)\end{array}$ & $\begin{array}{c}6.5 \\
(2.2- \\
11.7)\end{array}$ & $\begin{array}{c}4.1 \\
(3.5- \\
4.5)\end{array}$ \\
\hline
\end{tabular}


that those not invited for spirometry ("not at risk") had no COPD, and that the COPD prevalence for questionnaire nonresponders was the same (within each age group) as in questionnaire responders, the predicted number in the whole population would increase to 552, giving a prevalence of $4.1 \%$.

Estimated prevalence was examined for each age group. The maximum estimated prevalence was highest in those aged 60 to 69 years (14.7\%). In those aged over 40 years it was $9.6 \%$ (Table 2 ).

\section{Discussion}

This study used postal questionnaire and spirometry data to examine the prevalence of COPD in two general practice populations in an area with a high rate of socioeconomic deprivation. The overall estimated COPD prevalence was $4.1 \%$, with the highest estimated prevalence $-14.7 \%$ - seen in those aged 60-69 years. The populations were divided into age bands in order to take account of the relationship between age and onset of COPD, the differing response rates to the questionnaire, and differing attendance rates for spirometry between age groups. If population screening for COPD were to be considered, having a lower age limit of 40 years would seem appropriate since the youngest age group examined (age 30-39) had a prevalence of only $0.5 \%$ whereas subjects in older age groups had prevalences ranging from $6.4 \%$ to $14.7 \%$.

The study had several strengths. It was conducted in a realworld setting and recruited subjects from the community as a whole. There are few studies that have attempted to perform spirometry in the community in order to predict COPD prevalence. ${ }^{14}$ Prevalence estimates have traditionally relied on doctor diagnosis rather than spirometric measurements. ${ }^{5}$ The spirometry was performed in a standardised way with only five trained nurses carrying out the measurements, thus minimising bias. Subjects were enrolled on the basis of symptoms and smoking history rather than on medication or doctor diagnosis. Reversibility testing was used, although in light of the recent NICE guidelines ${ }^{15}$ this could be deemed to have been unnecessary.

There are a number of limitations to this study. An aggressive strategy was used to maximise recruitment, but despite this there was a poor response. In addition, a number of sources of possible bias need to be considered which could adversely affect the accuracy of the estimates. In predicting the population prevalence a number of assumptions were made: firstly, that no patient under 30 years of age suffered from COPD, which is likely to lead to a small underestimate of the COPD prevalence; and secondly, that the 825 patients who had spirometry performed had the same prevalence as the 1821 individuals who were invited but did not attend for the tests. Although we were unable to test this assumption formally, attenders had a higher proportion with "likely OAD" than non-attenders, which would tend to overestimate the prevalence. This was partly balanced by the finding that smoking was more common amongst non-attenders than attenders (Table 1). No data were available as to how many of these non-smokers were in fact ex-smokers - and therefore this finding may not be reliable.

It was also assumed that the 6828 adult responders to the questionnaire had a similar prevalence of COPD to the 3643 adult non-responders and that children would not have COPD. Responder bias to the postal respiratory questionnaire was examined in the 1993 survey. Compared to responders, non-responders were younger and less likely to have consulted their general practitioner (GP) in the previous year, but were similar with respect to gender, practice diagnosis of asthma and asthma-related treatment. ${ }^{16}$ It was not possible to examine characteristics of the non-responders to the 2001 survey other than age. The different response rates in each age group were accounted for in the method of estimating prevalence.

A number of patients with COPD may have declared themselves to be non-smokers on our postal questionnaires and also as having none of the key symptoms in 2001. This would lead to an underestimate in the prevalence of COPD.

One of the problems with comparing prevalence figures for COPD is that in some studies only older people are included in the denominator, ${ }^{6}$ whereas in others ${ }^{4,5}$ the whole population is used. We therefore calculated age-specific COPD prevalences which are presented in Table 2. These demonstrate higher prevalence figures for the older age groups than those seen in another UK study. ${ }^{6}$ If our prevalence figures were confirmed by future research, the high prevalence figures may have major implications for health planning and delivery.

In addition, although this study has shown a high estimated prevalence of COPD, it was carried out in a deprived area of Manchester and may therefore not be a reflection of COPD prevalence in other parts of the UK. Objective information from the UK concerning COPD prevalence is scarce. The only published UK study using spirometry in a general practice population examined only those aged 60 to 75 years and reported a prevalence of COPD of $9.9 \% .{ }^{6}$ In comparison, our figure for 60 to 79 year olds was $14.1 \%$. The study using the General Practice Research Database (GPRD) quoted the prevalence of diagnosed COPD in 1997 as $1.4 \%$ for women and $1.7 \%$ for men. ${ }^{5}$ The Office of Population Censuses and Surveys estimated a prevalence of $1 \%$ for COPD in the population. ${ }^{4}$

The importance of the difference between those estimates using doctor-diagnosed COPD and the figures presented in this 
paper could be disputed, since it could be argued that only those with less severe disease and minimal symptoms are the ones not getting a diagnosis. Although there may be no effective drug treatment for those with minimal symptoms and mild COPD, at the very least diagnosis would provide an opportunity to offer smoking cessation advice to the smokers. Smoking cessation is the only effective intervention which has been shown to slow the long term decline in lung function in those affected with the disease. ${ }^{17,18}$

Estimates based on patient records can only include diagnosed cases and it has been reported that up to $75 \%$ of COPD cases in general practice may remain undiagnosed. ${ }^{19}$ If there was this level of under-diagnosis in the practices contributing to the GPRD database, then the prevalence in that population would increase to $5.4 \%$ in women and to $6.8 \%$ in men, similar figures to the estimates found in our study.

If the assumptions made regarding non-responders and non-attenders are accurate, then this paper suggests that COPD is more common than previously demonstrated. In addition, if the age-specific prevalence figures are truly as high as those presented in this paper then this could have major implications for the way future health care and funding is planned. The challenge for general practice is to be aware of the problem of under-diagnosis, find these cases, correctly diagnose them, and then offer smoking cessation advice, treatment and follow-up.

\section{Acknowledgements}

The authors wish to thank the staff at Bowland Medical Practice and Tregenna Group Practice for their co-operation, and the patients who replied to the questionnaires. We would also like to thank Professor Phil Hannaford for reading and advising on the manuscript.

\section{Conflict of interest declaration}

TF has received fees from GSK, Boehringer Ingelheim, Schering Plough and AstraZeneca for speaking, funds for research from GSK, Boehringer Ingelheim, MSD and Schering Plough, funds for consultancy from GSK and Pharmacia, and travel grants from GSK, Boehringer Ingelheim, AstraZeneca, Chiesi Pharmaceuticals and MSD.

$\mathrm{MH}$ has received a fee from Boehringer Ingelheim for speaking, and travel grants from GSK, Boehringer Ingelheim and MSD.

ML has received travel grants from GSK.

JM has no conflicts of interest.

PF has received fees for attending symposia from GSK and MSD, funds for research from GSK, Boehringer Ingelheim and MSD, and travel grants from GSK, Boehringer Ingelheim and MSD.

\section{References}

1. Murray CJ, Lopez AD. Mortality by cause for eight regions of the world: Global Burden of Disease Study. Lancet 1997;349(9061):1269-76.
2. Mannino DM, Homa DM, Akinbami LJ, Ford ES, Redd SC. Chronic obstructive pulmonary disease surveillance - United States, 1971-2000. Respiratory Care 2002;47(10):1184-99

3. Celli BR, MacNee W. Standards for the diagnosis and treatment of patients with COPD: a summary of the ATS/ERS position paper. Eur Respir $J$ 2004; 23(6):932-46

4. McCormick A, Fleming D, Charlton J. Morbidity Statistics from General Practice:Fourth national study 1991-1992. Office of Population Censuses and Surveys. London: HMSO, 1995.

5. Soriano JB, Maier WC, Egger P, Visick G, Thakrar B, Sykes J, et al. Recent trends in physician diagnosed COPD in women and men in the UK. Thorax 2000; 55(9):789-94.

6. Dickinson JA, Meaker M, Searle M, Ratcliffe G. Screening older patients for obstructive airways disease in a semi-rural practice. Thorax 1999;54(6):501-05.

7. Frank PI, Wicks PD, Hazell ML, et al. Temporal change in the prevalence of respiratory symptoms and obstructive airways disease 1993-2001. Br J Gen Pract 2005;55(517):596-602.

8. Butler D, Frost L, Morris J, Spence M, Stevens R, Young A. Health Inequalities and Manchester in the 1990s. In: Stevens R, editor. Manchester: Manchester Health For All Working Party, 1993.

9. Frank TL, Hazell MF, Linehan MF, Frank PI. The diagnostic accuracies of chronic obstructive pulmonary disease (COPD) in general practice: the results of the MAGIC (Manchester Airways Group Identifying COPD) study. Prim Care Resp J 2006;15(5):286-93. doi:10.1016/j.pcrj.2006.07.007

10. Burney PG, Luczynska C, Chinn S, Jarvis D. The European Community Respiratory Health Survey. Euro Resp J 1994; 7(5):954-60.

11. Frank TL, Frank PI, Cropper JA, et al. Identification of adults with symptoms suggestive of obstructive airways disease: validation of a postal respiratory questionnaire. BMC Family Practice 2003;4(5) Epub.

12. National Heart Lung and Blood Institute, World Health Organisation. Global Initiative for Chronic Obstructive Lung Disease (GOLD) (2003). Global Strategy for the Diagnosis, Management, and Prevention of Chronic Obstructive Pulmonary Disease. Bethesda, 2005.

13. Efron B, Tibshirani RJ. An Introduction to the bootstrap. New York: Chapman and Hall, 1993.

14. Mannino DM, Gagnon RC, Petty TL, Lydick E. Obstructive lung disease and low lung function in adults in the United States: data from the National Health and Nutrition Examination Survey, 1988-1994. Arch Intern Med 2000; 160(11):1683-9.

15. National Institute for Clinical Excellence (NICE). Chronic obstructive pulmonary disease: national clinical guideline for management of chronic obstructive pulmonary disease in adults in primary and secondary care. Thorax 2004; 59(Suppl 1):1-232.

16. Frank $P$, Ferry $S$, Moorhead $T$, Hannaford $P$. Use of a postal questionnaire to estimate the likely under-diagnosis of asthma-like illness in adults. $\mathrm{Br} J \mathrm{Gen}$ Pract 1996;46(406):295-7.

17. Fletcher C, Peto R. The natural history of chronic obstructive airflow obstruction. BMJ 1977;1(6077):1645-8.

18. Doll R, Peto R, Boreham J, Sutherland I. Mortality in relation to smoking: 50 years' observations on male British doctors. BMJ 2004;328:1519-27.

19. Siafakas NM, Vermeire $P$, Pride NB, et al. Optimal assessment and management of chronic obstructive pulmonary disease (COPD). The European Respiratory Society Task Force. Euro Respir J 1995;8(8):1398-420.

Available online at http://www.thepcrj.org 